\title{
Dimensões históricas do documentário brasileiro no período silencioso ${ }^{1}$
}

Eduardo Victorio Morettin ${ }^{2}$

ECA-USP

\section{RESUMO}

$\mathrm{O}$ artigo pretende examinar a produção documental brasileira do período silencioso centrada nas cidades de São Paulo e do Rio de Janeiro, submetendo-a a recortes temáticos que transcendem a historiografia clássica do cinema brasileiro e que dialogam com a história cultural. Dois traços dominantes serão destacados: (1) a representação de eventos cívicos e espaços monumentais típicos a uma metrópole no Brasil nas primeiras décadas do século XX; (2) a representação dos festejos carnavalescos nas ruas (corsos, desfiles de clubes). Faz o exame rigoroso de um filme, Caça à raposa (1913), de Antonio Campos, a fim de verificar o padrão de ordem visual estabelecido em sua relação com o recorte proposto.

Palavras-chave: Cinema e história; Documentário brasileiro; Monumento e cinema.

\begin{abstract}
This article aims at examining Brazilian documentary production of the silent period, focused in the cities of São Paulo and Rio de Janeiro. This production follows thematic 'cuts' which transcend the classic historiography of the Brazilian cinema and which dialogue with the cultural history of the period. Two dominant traces of this production will be highlighted: (1) the representation of civic events and monumental spaces typical of a Brazilian metropolis of $20^{\text {th }}$ century's first decades; (2) the representation of Carnival on the streets. A more comprehensive analysis of the film Caça à raposa (1913), by Antonio Campos, is carried out with the objective of verifying the filmic visual pattern established in relation to the proposed thematic 'cuts'.
\end{abstract}

Keywords: Film and History; Brazilian documentary; Monument and cinema.

Uma das lacunas mais comentadas pelos principais pesquisadores que constituíram a historiografia do cinema brasileiro e a avaliaram é a referente ao estudo dos documentários da primeira metade do século XX, notadamente os do período do cinema silencioso. Há uma conhecida e lamentada dificuldade em travar contato com as imagens produzidas, o que explica por que, 
até o momento, elas não tenham sido, de maneira geral, objeto de estudos voltados para o seu conteúdo e estilo.

Paulo Emilio Salles Gomes apontava no final dos anos 70 o desconhecimento existente em relação à produção documental brasileira no período silencioso. Situação considerada surpreendente, pois já se sabia que o filme de enredo era a exceção, sendo a "continuidade do cinema brasileiro assegurada quase exclusivamente pelo documental". ${ }^{3}$ Jean-Claude Bernardet, no mesmo período, reforçava este quadro ao comentar que os historiadores de cinema privilegiavam a produção ficcional, privilégio que reflete mais a vontade tanto dos pesquisadores quanto dos cineastas de projetar sobre o passado uma linearidade cujo sentido desembocava na própria afirmação de um cinema brasileiro em busca de seu público, como veremos adiante. ${ }^{4}$

Os trabalhos de Vicente de Paula Araújo, A Bela Época do cinema brasileiro e Salões, circos e cinemas de São Paulo, ${ }^{5}$ permitiram que muitas das informações dispersas fossem reunidas e postas a serviço de um trabalho de catalogação exaustivo para o período que compreende os anos de 1897 a 1914 no caso de São Paulo e de 1898 a 1912 para a cidade do Rio de Janeiro. Sistematização ordenada pela cronologia, como a própria disposição dos capítulos indica. Em Salôes, por exemplo, encontramos: "1908 - O Crime da Mala e a Primeira Fita Cantante", "1909 — As Fanhosas Viúvas Alegres daquele tempo", e assim por diante. O relato desse pesquisador fez avançar o quadro sistemático do que foi produzido, mas apoiou-se em uma reprodução parcial ou integral das fontes escritas que consultou, sem considerações sobre as características de filmes a que não podia ter acesso. Livros de fundamental importância para o estabelecimento de uma filmografia acurada do cinema brasileiro do período, estas obras não trazem recortes outros que permitam ao leitor entender a referida produção dentro de um quadro mais amplo vinculado tanto à história cultural quanto à do cinema, pensada como um processo que não se resume à identificação de filme e de diretores.

Outro trabalho que analisa o cinema brasileiro dos primeiros tempos, compreendido entre os anos de 1896 e 1916, é o de José Inacio de Melo Souza, Imagens do Passado. São Paulo e Rio de Janeiro nos Primórdios do Cinema, livro editado pelo Senac em 2004. Vinculando o cinematógrafo ao contexto de modernização promovido pela recém-instituída República, examina a expansão do mercado exibidor em duas cidades, Rio de Janeiro e São Paulo, o impacto dessa ampliação sobre a produção de filmes brasileiros e a recepção crítica das películas aqui exibidas. Melo Souza traça um quadro geral das obras realizadas no país, cotejando-as com as de outras cinematografias aqui apre- 
sentadas e inserindo-as em um circuito cultural mais amplo, uma vez que o autor nos remete aos universos da música, do teatro e da imprensa. Ao mesmo tempo, propõe-se a revisar a periodização tradicionalmente adotada pela historiografia para abordar o momento. Para tanto, demarca nos capítulos iniciais dois legados com os quais prestará contas ao longo do livro, quais sejam, os campos construídos pela memória e pela história.

No entanto, não é objetivo do autor realizar uma análise dos filmes que sobreviveram. Além disso, a identificação temática da produção documental não constitui propriamente o foco de seu estudo, trabalho que se fosse feito permitiria adensar a reflexão proposta acerca do período, como veremos.

Para uma organização do olhar dirigido ao período que nos interessa, Bernardet ${ }^{6}$ propõe o trabalho com os chamados "filões" a fim de se contrapor à periodização adotada pelos historiadores de cinema, marcada profundamente pelo trabalho de Paulo Emilio Salles Gomes, Panorama do Cinema Brasileiro: 1896-1966. Nele, predomina o recorte que privilegia os momentos de conciliação entre a produção e o público, como foi o caso de sua "primeira época”, por exemplo. Ocorrida entre 1896 e 1912, ela representa a fase inaugural de uma harmonia que foi perdida pela ação de agentes externos. Neste sentido, recuperá-la no presente significa trazer de volta um tempo que o cinema brasileiro precisa reencontrar. Decorre desta visão a idéia de que

a Idade de Ouro e a sua reposição utópica precisam ser mediadas por etapas que levam de uma a outra, etapas estas que constituem a história degradada. $\mathrm{Na}$ periodização de Paulo Emilio parece quase sistemático o vínculo entre as épocas que estruturam a evolução do cinema brasileiro e a degradação, entendendo por esta uma interrupção da produção.?

Bernardet expõe a fragilidade de uma periodização que se acredita portadora de significado para todos os elementos que compõem o cinema propriamente dito (produção, exibição, crítica etc.). Esse aporte de sentido está relacionado com o próprio fio condutor que os agrupa, ou seja, a idéia de que se constrói uma nacionalidade a partir da experiência cinematográfica. Diversas são as fraturas expostas pelo autor nessa periodização, e a partir destas Bernardet levanta uma não menor quantidade de propostas e questões. Nosso objetivo não é a periodização, nem uma tentativa abrangente de caracterizar um perfil de toda a produção, mas promover um recorte mais pragmático de exploração do que sobreviveu para reunir dados que servirão de base para futuras articulações de conjunto. Por ora, é suficiente guardar as obser- 
vações de Bernardet quanto à necessidade de um olhar próprio a cada gênero de filme, dado que cada qual teve o seu ritmo e seu percurso, talvez exigindo uma periodização específica que contestaria os cortes cronológicos verticais feitos até aqui. Neste particular, cabe reforçar que o nosso foco é de caráter estético, naquilo que a estrutura das imagens tem de indicativo de uma postura social assumida pelos realizadores e seus patrocinadores.

Com o exame dos filmes, poderemos entender o cinema da época como uma expressão de valores, não só definidos pelo Tema mas, de modo mais decisivo, pela forma como foram concebidos os registros e sua organização em filme, seja na relação com o fato público, seja na que se faz com a vida privada. Há uma dimensão na percepção do estilo que envolve a comparação com um quadro mais amplo da produção internacional, no campo específico do cinema; e há uma outra dimensão que envolve o aspecto iconográfico da análise, ou seja, de que modo o cinema dialoga com outros suportes de veiculação de imagem que lhe são contemporâneos e que ajudam a compor o leque de opções que o contexto sócio-cultural oferece, ressalvado o estatuto que o objeto da análise (o filme) tem dentro de tal sistema de representações de um determinado período. Neste sentido, nos inspiramos na historiadora Jeannene Przyblyski que analisou as convenções narrativas estabelecidas pelo registro fotográfico de eventos históricos, examinando as fotografias de Eugène Appert sobre a Comuna de Paris. O cotejo com gravuras publicadas em periódicos da época matiza a abordagem indicial da imagem referida (pois a questão do "instantâneo" fotográfico não havia se colocado no momento da Comuna) e usa o contexto cultural para emoldurar uma análise mais precisa da "matriz de estruturas representacionais, já existentes e somente sonhadas, que a fotografia anexa, comprime, desloca e absorve".

Para citar algo semelhante em nosso contexto, podemos lembrar outro trabalho nosso, exemplo do referencial teórico crítico aqui apresentado. A sua fonte é Descobrimento do Brasil, filme de Humberto Mauro, realizado em 1937. ${ }^{9}$ Ao traçar os percursos que o tema do Descobrimento atravessou no decorrer do século XIX e nas primeiras décadas do século XX, situa o quadro de referências dentro do qual a obra do diretor mineiro foi pensada. Esse quadro é amplo e diversificado, passando pela produção dos principais historiadores do século XIX e pelas representações iconográficas elaboradas pelos pintores acadêmicos ligados às instituições de cultura do Império e da nascente República. Tais vínculos tornam-se evidentes através de uma primeira 'vista' da obra do diretor mineiro por meio da presença de Afonso de Taunay entre os colaboradores intelectuais do projeto, o que já remete a uma deter- 
minada tradição historiográfica da qual o então diretor do Museu Paulista fazia parte, e que tinha por núcleo central Francisco Adolfo de Varnhagen, João Capistrano de Abreu e a produção do Instituto Histórico e Geográfico Brasileiro. Além disso, o filme pretendia ser uma visualização da carta do escrivão Pero Vaz de Caminha, pressupondo uma certa leitura e apropriação de um documento cujo histórico também é feito. Por fim, Descobrimento recorre como fonte de composição de seus planos e suas seqüências a diversas pinturas, sendo A Primeira Missa no Brasil (1861), de Victor Meirelles, a citação mais clara. O filme de Mauro insere-se, portanto, dentro de uma tradição já estabelecida, sendo apresentado pelos gestores do projeto como seu portador e herdeiro. Percebê-la criticamente teve como resultado o desvendamento de algumas das opções que a obra tinha à sua disposição para dar continuidade ao tema, fornecendo subsídios para uma melhor compreensão de sua especificidade em relação a alguns dos materiais que lhe serviram de suporte.

\section{O DOCUMENTÁRIO}

Do final dos anos 70 até a atualidade os estudos referentes ao gênero documental avançaram de maneira significativa, devido, entre outros motivos, à reconhecida importância de obras como as do cineasta Eduardo Coutinho. A produção é variada, destacando-se textos onde ora predomina a análise fílmica, como o pioneiro trabalho de Jean-Claude Bernardet, ora a contextualização histórica, ou a perspectiva autoral. ${ }^{10}$ Estudos desenvolvidos acerca de conjuntos documentais produzidos por instituições governamentais também tiveram seu lugar. ${ }^{11}$

Rubens Machado, por sua vez, em trabalho ainda inédito, discorre sobre a representação cinematográfica da metrópole paulista no período silencioso, conferindo grande parte de seu esforço analítico ao exame de São Paulo, Sinfonia da Metrópole (1929), de Alberto Kemeny e Rudolf Rex Lustig, e Fragmentos da Vida (1929), de José Medina. Também são considerados Exemplo Regenerador (1919), de José Medina e O Segredo do Corcunda (1924), de Alberto Traversa. ${ }^{12} \mathrm{O}$ autor relaciona as diversas determinações presentes na questão da representação fílmica da cidade: a influência de matrizes construídas pelo cinema estrangeiro; a presença de uma série de contradições emergentes daquilo que Paulo Emilio qualificou como "incompetência criativa de copiar"; ${ }^{13}$ a participação de estrangeiros na produção artística cinematográfica. E acentua, por exemplo, o anseio de verticalidade presente em Sinfonia e o 
seu distanciamento daquilo que corresponderia ao desenho arquitetônico da cidade então. ${ }^{14}$ Neste caso, temos um exame da forma pela qual os elementos da natureza são incorporados aos filmes apenas quando disciplinados na disposição dos parques e jardins. Como afirma o autor:

Os vazios entre os prolongamentos ocupados do solo urbano, mantidos por mecanismos de especulação imobiliária, ajudam a explicar o fato de não terem Kemeny e Lustig nos honrado com planos aéreos da capital, nada difíceis tecnicamente para eles. E nos dão uma indicação do drible que os cinematografistas paulistanos de uma forma geral deviam dar naqueles terrenos baldios e aspectos mais bucólicos imediatamente adjuntos aos setores mais soberbamente edificados daquela São Paulo. A natureza é banida da São Paulo cinematográfica no que toca à presença cênica da vegetação, só disponível na disciplina de jardins bem tratados - critério extensivo urbi et orbi a quintais, chácaras e sedes de fazenda. (São Paulo em Movimento, p.101)

Tudo o que não corresponde ao ideal de trabalho dentro da ordem é excluído da representação: violência urbana, miséria, movimentos sociais. Machado acredita que o entendimento desses filmes poderia ser enriquecido com o cotejo a uma produção cultural mais conservadora, próxima dos círculos do poder. Para ele, as

atas das sessões públicas dos mandatários e os 'sermões encomendados' das cerimônias oficiais, um documento subscrito pelo empresariado ou o 'Plano de Avenidas' de Prestes Maia, na interpretação daquela São Paulo cinematográfica, talvez rendesse paralelos mais profícuos que, digamos, um cotejamento com as Novelas Paulistanas de Alcântara Machado, escritas de 1924 a 1930. (São Paulo em Movimento, p.103)

Temos, portanto, como pano de fundo deste artigo as obras que traçam um panorama do cinema brasileiro silencioso, incluindo a produção documental, no período que se estende até o ano de 1916, e o contexto geral de reflexão sobre o documentário. No que tange ao documentário do período silencioso, há a referência do trabalho de Rubens Machado, que analisa um filme que não será objeto direto de nossa investigação por possuir cópias de difusão e por não atender ao ineditismo presente na nossa relação de filmes. Dentro deste quadro, constatamos a ausência de análises sobre as reportagens cinematográficas e os documentários centrados nas grandes cidades. Os le- 
vantamentos e discussões feitos por Araújo e Melo Souza não abarcam o período que vai de 1916 até a transição do cinema silencioso ao sonoro, concretizada no Brasil, grosso modo, no início da década de $1930 .{ }^{15}$

\section{A CRÍTICA DE CINEMA E A IMAGEM DESEJÁVEL}

Tomando o quadro geral da cinematografia das primeiras décadas do século XX, não será esquecido nesta análise formal o problema das condições de produção: a fragilidade existente na fatura dos filmes pela dificuldade em obter os recursos exigidos para reproduzir com precisão os modelos cinematográficos da época, principalmente no que diz respeito aos aspectos técnicos, como o cenário, as vestimentas, a necessidade de filme virgem, o equipamento necessário para a filmagem, iluminação e captação do som, cada vez mais sofisticados e caros. Realizado por imigrantes e/ou em centros afastados das grandes cidades, o cinema apresentava para as suas platéias uma imagem de difícil assimilação, não por força dessa fragilidade material que nos interessa, mas porque exposição involuntária de nossos problemas sociais ou daquilo que se considerava atrasado, rural ou anti-higiênico. Neste sentido, é lapidar uma fala de Guilherme de Almeida a respeito da produção de filmes no Brasil no final dos anos 20. Ao elogiar e apontar a singularidade do citado São Paulo, Sinfonia da Metrópole, traça um panorama nada favorável. Como diz:

Que foi? Algum dramalhão creoulo, com bugres, pretos e gallegos insupportaveis? Algum horror patriotico, com figurões nacionaes fazendo cocegas na historia e no resto da humanidade? Algum caipirismo grotesco, com tatus sorrateiros, enlambuzados de terra vermelha, escorregando ou trepando por literaturas lamentaveis? Algum hysterismo melindroso e almofadado, com toalhinhas de croche, cadeiras austriacas e 'cache-pots' degradantes, nos interiores theatraes, e costelletas ou 'accroche-coeurs', olheiras ou 'ratazanas' nas caras tambem theatraes? ... Que foi? ${ }^{16}$

Afora a dura crítica ao chamado filme histórico, os termos "dramalhão creoulo", "caipirismo grotesco" e "hysterismo melindroso e almofadado", presentes no artigo de Guilherme de Almeida, indicam que o problema estava na incômoda distância entre os filmes brasileiros e os grandes "monumentos” do cinema da época. Havia uma percepção em geral negativa acerca do que era realizado aqui, pelo menos do ponto de vista daqueles que ocupavam 
as posições-chave dentro dos periódicos e das instituições culturais reconhecidas pelo governo e pela sociedade.

O que nos interessa nessa rejeição ao produto local é a inquietação a respeito da imagem do país apresentada pelo cinema. Sobre o filme O Brasil Potência Militar (1925), produzido pela Botelho Filme, a revista Selecta, de 13 de janeiro de 1926, comenta:

Que fizessem um filme mostrando a pujança das nossas forças armadas, muito bem, o governo teria nisso um auxílio para captar ainda mais as simpatias do público e principalmente dos sorteados que não cumprem com o seu dever, preparando-se para servir à Pátria, quando possível. Mas, em vez disso, apresentam algumas evoluções dentro dos quartéis, letreiros e mais letreiros de fraseologia elogiosa aos nossos oficiais, com partes e mais partes de grupos parados, como se os dirigentes do nosso Exército precisassem disso, para ter conhecido o valor. ${ }^{17}$

O incômodo provocado pela película não diz respeito apenas à quantidade excessiva de letreiros, pois à "fraseologia elogiosa" não correspondem imagens dignificantes do Exército. A maneira pela qual o aparelhamento das Forças Armadas é mostrado também não é bem acolhida. $O$ desgaste para com o filme aumenta diante da opção feita pelo realizador em fotografar o "desfile de tropas pelo Campo de São Cristóvão num dia de trabalho, com o evidente ou impressionante intuito de demonstrar que nenhum interesse tem o povo brasileiro pelos seus defensores". ${ }^{18}$

Em Operações de Guerra (1925), de Luiz Thomaz Reis, que registra a campanha do Paraná em operações militares contra os tenentes em 1924, Selecta, de 10 de fevereiro de 1926, observa: "Não sabemos se o presente trabalho se destina a ser mostrado noutros lugares, e por isso pedimos que o revejam os seus confeccionadores, para que possam aquilatar quão vexatório é, para nós, vermos os nossos soldados marcharem descalços, com diversas formas de vestimentas". ${ }^{19}$

Ao autor da crítica pouco importa a situação real em que se encontram os soldados durante a campanha militar, preocupando-se apenas com a imagem do exército transmitida pelo filme ao público. Desfiles em ruas vazias aliado às vestimentas e às armas precárias não contribuíam para construir mentalmente a representação de uma instituição sólida, cuja tarefa é a de zelar pelo cumprimento da ordem em todo o país.

Esse desajuste entre o trazido pela imagem e o desejado pela crítica é acentuado pela comparação com o cinema americano, modelo de cinemato- 
grafia, eixo em torno do qual partem as reclamações a respeito do que não se faz e deveria ser feito, do que deve ser mostrado ou não. Octávio Mendes, em artigo de 1932, ao discorrer sobre a presença desses filmes na sociedade, pontua melhor a importância da construção simbólica realizada pelo cinema para a consolidação de determinadas imagens. Para ele,

A gente sente o mal [ $s i c$ ] aspecto de um batalhão em marcha, quando há desigualdades de altura. Sem querer a gente pensa num corpo do exército americano que a gente viu em Film. Homens grandes. Fortes. Todos quasi da mesma altura. Mas ninguem se lembra de espreitar os marujos de qualquer navio de guerra americano que passa pelo nosso porto. Há baixos e altos. São iguais a todos! O Cinema é que dá essa poderosa impressão que tanto beneficia um paiz! Póde-se dizer sem susto, mesmo que o Cinema Americano teve o poder de fazer os Estados Unidos o primeiro paiz do mundo. ${ }^{20}$

A crítica de Mendes, ao valorizar o papel da propaganda, parece não dimensionar a efetiva distância entre a situação econômica de um país e a sua representação cinematográfica. Invertendo a ordem dos produtos posta pelo autor, afirmamos que o fato de os Estados Unidos serem "o primeiro paiz do mundo" fornece condições para que os seus filmes representem este dado, e não o contrário. Neste caso, como também no de outras cinematografias, a expressão dessa primazia por meio do cinema se manifesta pelo domínio de um método refinado de narração e pela própria idéia de cinema-espetáculo que mobiliza recursos técnicos afirmadores dessa superioridade, constituindo o trabalho de David Griffith uma boa lição a ser seguida. ${ }^{21}$

Em nosso contexto, os chamados filmes naturais, dedicados aos aspectos de nossa natureza e da vida nas fazendas e nas cidades, constituíam mais uma oportunidade para visualizar o indesejável, dado que as condições de controle sobre o objeto de filmagem eram mais precárias do que em "estúdio". Acerca de Brasil Pitoresco — Viagens de Cornélio Pires (1925), a revista Selecta faz um severo julgamento de Cornélio Pires, que

achou apenas de bom nesta cidade [Salvador] a sórdida reunião de gente humilde na feira de Água de Meninos, os aspectos da rampa do cais do Modelo; o negócio das frutas por meio de jericos, pelos nossos lavradores rurais, dando apenas, como ficha de consolação, uma impressão das comemorações patrióticas do dia 2 de julho ... e outra do gabinete de Medicina Legal, na Faculdade de Medicina. O excursionista, que tão cabotino se revelou, exibindo-se caricata- 
mente em todos esses lugares, não quis ver senão abencerragens de raças quase extintas, aspectos e lugares inferiores, para aludir, tão somente em legenda, que a cidade tem jardins, asfaltos e outros melhoramentos...22

Porém, houve quem gostou. A crítica de O Estado de S. Paulo, de 28 de janeiro de 1926, elogiou a opção de não filmar "belezas de praças e jardins, riquezas de palacetes ou aspectos da alta sociedade. Fez questão de só filmar aspectos típicos, danças e exercícios de capoeiragem, trabalhos de vaqueiros e hábitos de cangaceiros, em suma: coisas pitorescas do Brasil". ${ }^{23}$

Por isso, atribui ao filme um caráter "instrutivo", recomendando-o aos seus leitores, pois "não vão pois apreciar uma fita da cidade, nem de coisas estrangeiras, mas uma fita de nossa vida real de brasileiro obscuro, que trabalha para a riqueza do País". ${ }^{4}$

A oscilação em torno do filme demonstra, por sua vez, um outro tipo de demanda, desta feita vinculada à necessidade de trazer à tona a "vida real do brasileiro obscuro" com o objetivo de que o público das cidades tenha contato com o imenso Brasil desconhecido, título, aliás, de um filme de 1925. Um anseio pelo voltar-se para o interior do território dentro de um movimento de busca da nacionalidade marcará o debate intelectual sobre o problema nos anos 30, e o cinema já indicava essa possibilidade com a realização de uma verdadeira corografia fílmica do país, tal como indicado em Brasil Pitoresco. ${ }^{25}$ Essas questões animarão a discussão sobre o papel dos complementos cinematográficos no processo de integração desejado pelo governo Vargas e sobre o uso do cinema em sala de aula dentro da tônica do exigir imagens limpas, indicadoras de progresso e desenvolvimento. Brancura, decência e ingenuidade caminham juntas na exigência de uma imagem cinematográfica que cristalize uma determinada visão de Brasil. Em torno destas e de outras características a crítica especializada e os educadores se unirão para criar um cinema que se afaste dos filmes feitos até então, um cinema digno daquilo que é idealizado para o conjunto da sociedade como imagem desejável desta, ou seja, como um monumento.

O mal-estar e o preconceito diante do cinema brasileiro encontravam outro fator: o fato de ser uma produção a que se dedicavam imigrantes olhados com desdém pela elite da sociedade. Há a acusação de o cinema ser "pouco brasileiro", conforme nos informa Maria Rita Galvão,

entre outros motivos, porque feito por estrangeiros (claro que não se trata do 'bom estrangeiro'). O que aliás por vezes é dito de modo menos delicado, que 
salienta a carga preconceituosa; neste sentido, uma das características do cinema nacional em que a crítica paulista se apóia para desprezá-lo é o fato de ser um cinema de 'carcamanos' - e esta expressão, por sua vez, de imediato nos reconduz ao 'popular': em São Paulo dos anos 20, carcamano é o operário. ${ }^{26}$

Maria Rita Galvão lembra que os imigrantes não eram os únicos a fazer cinema em São Paulo. Havia também pessoas que pertenciam a um círculo mais erudito da cultura paulistana, distinto também no âmbito econômico e social, como Menotti del Picchia, Canuto Mendes de Almeida, Octavio Gabus Mendes, Antônio Tibiriçá e Armando Leal Pamplona. Estes, no entanto, não conseguem fazer um cinema diferente daquele que os diretores Arturo Carrari e Gilberto Rossi realizavam.

Carrari ou Rossi (ou quaisquer outros que os valessem) eram condição sine qua non para que se fizesse cinema. Quem quer que pretendesse fazer cinema era obrigado a associar-se a qualquer deles - não havia outros disponíveis ou pelo menos a ingressar no sistema de acordo com as regras estabelecidas, isto é, a comportar-se exatamente como Carrari ou Rossi. ${ }^{27}$

A associação de todos esses fatores impedia que o cinema se constituísse no veículo de divulgação de nossas pretensas qualidades, impedimento sempre ressaltado pela crítica, preocupada com a imagem da cidade e do país, interna e externamente. O episódio mencionado por Galvão, exemplo do problema geral da "cavação" que tanto incomodava os críticos, torna patente que as dificuldades enfrentadas pelos cineastas iam muito além das de ordem econômica, revelando, por sua vez, uma pressão maior dos poderes instituídos para que houvesse um maior controle sobre o processo de produção de imagens.

Uma das questões que pode ser verificada em pesquisas futuras diz respeito às possíveis tensões entre ao projeto de institucionalização do espetáculo cinematográfico no Brasil e a presença de elementos populares nos cinemas da época, questão que está no centro das preocupações dos críticos e governantes quanto à imagem do país oferecida pelos filmes, uma vez que está em pauta a ideologia da "higienização" e a vontade de tornar o cinema uma dupla vitrine do progresso nacional, pelo que ele expressa no próprio fato de estar sendo produzido no país e pelo que ele "mostra" da paisagem urbana e das instituições brasileiras.

A necessidade de controle pode ser avaliada a partir do exame de um pequeno filme como O que foi o carnaval de 1920 (1920), filmado por Alberto 
Botelho. Essa duplicidade é patente no momento em que a câmera procura circunscrever seu campo ao carro que participa do corso. Esse esforço no enquadramento diz respeito à presença de elementos populares que se acotovelam ao redor do automóvel, sugerindo uma certa tensão na imagem e, por conseguinte, no desfile.

No caso dos documentários pertencentes ao acervo da Cinemateca Brasileira, como O que foi o carnaval de 1920 (1920) e Rio - Anos 20 - Carnaval (1922-1926), o retrato dos corsos tinha por objetivo apresentar a diversão do pequeno grupo detentor dos carros e que ostentava nas vias públicas suas posses. Como informa Nicolau Sevcenko a propósito do Carnaval em São Paulo, contexto diferente, mas passível de aproximação, os festejos na região da Paulista e do Triângulo nos anos 10 eram mais comedidos, trazendo "consigo um claro limite de forma, para além do qual todo excesso se tornava aparente e comprometedor. Era um Carnaval com receituário prescrito, posições marcadas e coreografia de gestos e movimentos prefigurados". ${ }^{28}$ A presença de populares, tal como já indicada, traz um elemento perturbador à ordem prescrita.

A questão da imagem do Carnaval envolve o cotejo de tais representações com o contexto geral de políticas de higienização e disciplina praticadas pelo poder público e pela imprensa, com posturas de desconfiança perante a "desordem" que incluam a própria experiência do cinema, vetor significativo da vida urbana. José Inácio de Melo Souza, em Imagens do passado, observa, por exemplo, a formação de um público de elite nos cinemas da cidade do Rio de Janeiro na primeira década do século XX. Levando-se em consideração as reformas urbanísticas empreendidas por Pereira Passos na região central da cidade, que tiveram como conseqüência a expulsão das pessoas mais pobres para as encostas dos morros e a substituição dos antigos casarios e cortiços por largas avenidas e instituições-símbolo da nova ordem cultural, a saber, os prédios que abrigaram o Teatro Municipal, a Biblioteca Nacional e a Escola Nacional de Belas Artes, as tentativas de barrar o acesso democratizado ao espetáculo cinematográfico parecem consoantes com o tom dado pelas classes dominantes de então. Os novos cinemas, construídos na avenida Central, depois Rio Branco, deveriam abrigar em suas salas um público que não fosse negro, caipira, caboclo e pobre de maneira geral. Aliás, necessidade de afastamento que era comum aos espaços constituídos pela burguesia carioca. O papel da imprensa não se resumia a criticar determinados tipos de comportamento. Tratava-se de indicar as salas de cinema bem freqüentadas, atri- 
buir um caráter educativo e científico ao novo invento a fim de torná-lo palatável ao gosto de uma burguesia a ser conquistada para o meio.

No que diz respeito aos festejos carnavalescos, deve-se destacar ainda que a historiografia sobre os registros cinematográficos dessas festividades populares no período abarcado por este artigo é rarefeita. Temos trabalhos que se ocupam da produção ficcional que recorria ao acompanhamento sonoro durante o período silencioso e podemos afirmar que mesmo essa reflexão carece ainda de consistência. O objetivo, neste particular, é examinar o padrão visual de registro, as escolhas do que e como filmar, tarefa paralela a outros percursos já feitos na análise do filme de ficção e da comédia musical nos quais o pesquisador se concentra nas relações entre música popular e cinema, na composição dos tipos populares ligados ao mundo do samba (como o malandro), destacados em função de um certo conceito de identidade nacional do brasileiro que privilegia a subversão de hierarquias sociais (por exemplo, o "zombar" da cultura erudita, a paródia).

Propomos, portanto, o caminho de se concentrar a análise nas fontes documentais e em seu diálogo, enquanto imagens, com outras formas de representação do popular na época, verificando o teor das transposições. É o momento de sugerir um recorte possível dentro da filmografia referente ao documentário brasileiro no período silencioso, a saber, o processo de monumentalização das imagens, perceptível nos filmes que representam comemorações cívicas e naqueles que se referem ao universo das elites da época, este último conjunto examinado a partir de Caça à Raposa (1913), de Antonio Campos.

\section{A MEMÓRIA, A DISTINÇÃO SOCIAL E O MONUMENTO}

Um dos recortes possíveis, e mais tradicional dentro da historiografia do cinema brasileiro, recai no produtor das imagens, diretor ou companhia produtora. Por um lado, ele nos permite identificar certos traços estilísticos entre alguns dos responsáveis pelos filmes que sobreviveram ao tempo, como é o caso de, entre outros, Alberto Botelho, Igino Bonfioli, José Borin e Gilberto Rossi, pesquisa que por sua vez nunca foi feita. Por outro, esse procedimento é ardiloso, pois se confere um estatuto de autoria a um trabalho que na época era desprovido deste cunho, como vimos. Esses cineastas mal eram vistos como diretores, quanto mais autores. Neste sentido, é necessário pensá-los dentro de outro referencial no qual as questões de estilo estejam vinculadas às te- 
máticas da história cultural, como o das mudanças provocadas pela percepção de um novo tempo (modernidade) e suscitadas também pelo surgimento e consolidação do cinematógrafo.

Esta história cultural da modernidade tem um palco: a metrópole urbana. Como afirmam Leo Charney e Vanessa Schwartz,

o surgimento de uma cultura urbana metropolitana que levou a novas formas de entretenimento e atividade de lazer; a centralidade correspondente do corpo como o local de visão, atenção e estimulação; o reconhecimento de um público, uma multidão ou audiência de massa que subordinou a resposta individual à coletividade; o impulso para definir, fixar e representar instantes isolados em face das distrações e sensações da modernidade, um anseio que perpassou o impressionismo e a fotografia e chegou até o cinema; a indistinção cada vez maior da linha entre a realidade e suas representações; e o salto havido na cultura comercial e nos desejos do consumidor que estimulou e produziu novas formas de diversão. ${ }^{29}$

No exame do material aqui focalizado, há que se verificar como a cidade e seus eventos são representados como espaço de celebração da modernidade e como espaço em que se reproduz uma clara divisão social entre o que é objeto primeiro do olhar da câmera (teatros, hospitais e edifícios públicos identificados com o progresso e bom gosto burguês) e aquilo que pela sua presença institui um elemento de tensão, ou seja, a presença de elementos populares. Cabe verificar a relação entre o que acontece nos documentários brasileiros e o que já se verificou no caso dos filmes europeus onde, nas tomadas de atos cívicos, a câmera pode ficar mais alta para "ver mais" do que o público que fica um pouco abaixo, compondo a moldura como multidão disciplinada. $\mathrm{Na}$ observação dos monumentos e nas situações de parada militar, por exemplo, é comum compor-se o quadro de modo a ressaltar os espectadores, o estatuto de nobreza da estrutura ou evento mostrado pela sua "posição" diante do habitante da cidade. Num filme dos Irmãos Lumière, ainda dentro do "primeiro cinema”, a estátua de Henrique IV, em Paris, é observada por uma câmera que fica distante, do outro lado da avenida, de modo a ter o movimento da rua entre nós e o monumento para ressaltar sua posição mais alta e imobilidade diante da contingência do mundo abaixo; atrás da estátua e de seu pedestal, um enorme imóvel clássico para ressaltar a tradição e, no canto direito do quadro, a Pont Neuf, reunindo então três temas: a memória, a engenharia e a vida das ruas. Claro que, nas décadas subseqüentes (lembrando 
aqui que os filmes referidos por este artigo chegam até os anos 20), a linguagem evoluiu e os registros envolviam mais do que a tomada única com câmera fixa, mas a produção brasileira, pelos dados que temos, ainda se encontrava mais próxima do padrão da primeira década do século XX do que da sofisticada montagem de um Dziga Vertov ou de um Walter Rutmann. Cabe, enfim, verificar o padrão de "ordem visual" presente nos títulos relacionados ao recorte proposto, o senso de controle (enquadramento, movimentos) e de equilíbrio (o que se entende como o melhor ponto de vista diante de cada assunto) aí afirmados. Há um modo de buscar o efeito de sentido diante do espaço urbano, seus monumentos e festas, ressaltando-se que nossa observação estará especialmente dirigida ao tratamento dado à população posta em foco. Neste sentido, a análise comparativa é de grande auxílio e permite considerações sobre o que é uma "opção de estilo" e o que é "traço natural" na época, seja no olhar dirigido ao espaço público, ou mesmo quando se tratar de filmes da vida privada.

Em relação ao que define a composição da imagem desejada, como efeito de distinção ou propaganda, vale lembrar o contexto mais geral das relações internacionais e da posição de cada país diante do ideal de progresso. A seu modo, o cinema feito no Brasil nos anos 20 e no início dos anos 30 guarda nítida relação com uma tendência mundial a se fazer do cinema uma "vitrine", um ponto de celebração das virtudes nacionais no concerto (ou desconcerto) das nações. Quando se observam alguns filmes daquele período, bem como textos e declarações da época, vindos dos Estados Unidos ou da Europa, constata-se a força com que se toma o espetáculo cinematográfico como uma questão de orgulho nacional, dada a condensação de pujança econômica, avanço técnico, talento artístico e competência administrativa presente no cinema. Essa tendência chega ao paroxismo no caso das superproduções, dos grandes espetáculos, estes que tomam o número de figurantes, a escala dos acontecimentos narrados, a envergadura dos heróis, a monumentalidade da cenografia e a engenhosidade dos efeitos como vitrine especial em que a Nação se espelha, diante de si e dos outros. Nas primeiras décadas do século, mais até do que hoje, a competência técnica e discursiva (em termos do domínio de procedimentos narrativos específicos) de uma cinematografia significava progresso nacional, superioridade, numa competição que transferia para a nova arte aquele papel desempenhado pelas Exposições Universais. Estas, que tiveram seu momento maior de impacto na virada do século, eram ocasiões de festejo e celebração das proezas da indústria, de exaltação do mundo das mercadorias cada vez mais amplo e diversificado, de medida do pro- 
gresso das Nações e de sua luta pela hegemonia. Enquanto tais, eram sinais de uma "carnificina do espírito" que não demorou, sob a égide do nacionalismo, a se transformar em efetivo banho de sangue em 1914. Como os pavilhões nacionais, como as novas máquinas, o novo grande espetáculo visual apoiado em alta tecnologia se projetou nas telas para assumir a dimensão de monumento, espécie de alegoria nacional antes mesmo de se considerar o conteúdo de experiência humana focalizado por suas representações. Filmes como Cabiria (1914), de Giovanni Pastrone, O Nascimento de uma Nação (1915) e Intolerância (1916), ambos de David Griffith, Metrópolis (1927), de Fritz Lang, Napoleón (1927), de Abel Gance, e Outubro (1927), de Sergei Eisenstein, constituem verdadeiras obras-monumento nacionais em todos os sentidos, cercadas pela exaltação da vocação do cinema para absorver mitologias, cercada das referências aos prodígios técnicos e a todo o conjunto de invenções. ${ }^{30}$

O esforço das sociedades em construir uma memória de si através da mobilização de imagens referidas ao passado ou fincadas na afirmação de um domínio tecnológico nos leva a interrogar sobre o próprio estatuto de memória adquirido por esse meio de comunicação de massas. Christian-Marc Bossérro observa que o cinema, já em seus primeiros tempos, aparecia como elemento de registro da memória a ser trabalhado pelo historiador. Segundo esse autor,

les premiers projets de cinémathèques virent le jour au tournant du siècle, conçus de manière strictement documentaire pour archiver l'image des grands événements, des grands personnages, des lieux notables et des civilisations lointaines. Illustration parfaite de cette conception du cinéma comme machine mémorielle, un projet de 1908, en France, propose de munir les cimetières de services cinématographiques où les familles des défunts viendraient les voir ressuscités à l'écran. Instrument de mémoire donc avant que d'être instrument de fiction, le cinéma s'inscrivait, d'emblée, dans le siècle comme l'une de ses futures archives. ${ }^{31}$

O aspecto documental viria da percepção de que as imagens captadas pela câmera retratariam o real, permitindo o registro de memória de eventos, personagens e ações que constituiria documento a ser transformado em História pelos profissionais competentes, como se não houvesse mediação de nenhuma espécie entre o sujeito e seu objeto e como se esse olhar não dialogasse com outras matrizes de representação. A utilização do filme como veículo de transmissão de conhecimentos dentro de um projeto que previa o seu uso 
para fins educativos, aliada à produção cinematográfica de reconstituições de época, agregam à idéia já exposta uma outra dimensão, dado que não se trata tão-somente de captar as efemérides do momento, mas de celebrar por meio de filmes de "ficção" aquelas comemorações que fazem parte do imaginário de uma determinada sociedade. Integrante de uma corrente cujo elo reside na vontade de ampliar as fronteiras de circulação do saber histórico, atribuindo novos papéis ao fazer do historiador, o cinema incorpora-se a um circuito de produção e perpetuação da memória, cristalizado nos museus e monumentos destinados à visitação pública. Expressando a vontade de "parar o tempo ... bloquear o trabalho do esquecimento, fixar um estado de coisas, imortalizar a morte, materializar o imaterial", ${ }^{32}$ o cinema é lugar de memória, é a "machine mémorielle" do século XX.

Dentro deste quadro e analisado dessa perspectiva, o cinema espelha a vontade de justificar as ações do presente à luz das projeções iluminadoras do passado ${ }^{33}$ e de garantir para as gerações futuras, por meio de constantes exibições em diferentes espaços e para muitos espectadores, a efetividade da construção simbólica que faz do tema a permanência de sua imagem. Por isso, essas obras constituem um esforço de monumentalização do passado, e como monumentos devem ser analisados. Como observa Jacques Le Goff, a ampliação do universo documental à disposição do historiador não deve desviá-lo de sua rota, a saber, a da "crítica do documento - qualquer que ele seja - enquanto monumento". ${ }^{34}$ Para esse autor, tendo em vista o trabalho do medievalista que busca uma história total, é necessário repensar a própria noção de documento, pois

O documento não é inócuo. É antes de mais o resultado de uma montagem, consciente ou inconsciente, da história, da época, da sociedade que o produziram, mas também das épocas sucessivas durante as quais continuou a viver, talvez esquecido, durante as quais continuou a ser manipulado, ainda que pelo silêncio. O documento é uma coisa que fica, que dura, e o testemunho, o ensinamento (para evocar a etimologia) que ele traz devem ser em primeiro lugar analisados desmitificando-lhe o seu significado aparente. O documento é monumento. Resulta do esforço das sociedades históricas para impor ao futuro - voluntária ou involuntariamente - determinada imagem de si próprias. ${ }^{35}$

Perceber a tentativa de constituição de um novo monumento permitirá a definição do papel desempenhado pelos filmes que retratam comemorações cívicas e cortejos fúnebres de personalidades políticas naquilo que Luís 
Reis Torgal qualificou como o "discurso divulgativo da história". Esse discurso "conduz, naturalmente, a uma memória histórica ... que, como todas as memórias, deforma, amplifica, esbate ou apaga, de acordo com a força de recepção e da transmissão". ${ }^{36}$

Há um enorme distanciamento entre as produções aqui referidas e o cinema nacional, cuja marca nesse período é mais precária. No entanto, em documentários como Barão do Rio Branco - A Nação em luto - Os Funeraes (1912), Exposição Nacional do Centenário da Independência no Brasil em 1922 (1922), Ipiranga (1922), Trasladação das cinzas de Estácio de Sá (1922), Funerais de Rui Barbosa (1923) e O Novo Palácio da Câmara dos Deputados (1926) certamente há essa vontade de perpetuação pela imagem cinematográfica de determinada memória histórica, cuja veiculação pelos cinemas constituía um esforço de ampliação do evento que tinha por palco as ruas da cidade moderna.

Trataremos agora de um pequeno filme no qual as elites tornam a cidade seu teatro, elaborando imageticamente uma representação a ser transmitida aos outros segmentos sociais. Cabe, enfim, empreender a análise fílmica de um dos títulos remanescentes, identificando por intermédio da imagem elementos que nos remetem ao quadro mais geral da história.

\section{O LAZER DAS ELITES: CAÇA À RAPOSA (1913), DE ANTONio CAMPOS}

Como referido no próprio título, o pequeno filme realizado em 1913 pela empresa Campos Filme, dirigida por Antonio Campos, trata da expedição organizada por Olívia Guedes Penteado nos campos do Barro Branco, informação que nos é dada no letreiro de abertura, funcionando como uma espécie de título secundário. ${ }^{37}$ A princípio, sem travar ainda conhecimento com os dados que nos serão fornecidos pela imagem, causa estranheza ao espectador de hoje, e provavelmente aos que assistiram à reportagem cinematográfica na época, a realização de uma caça à raposa em plena cidade de São Paulo. Espera-se, portanto, que explicações sejam dadas a respeito da natureza do evento no desenrolar da narrativa.

O letreiro seguinte relata a partida, do Jardim da Aclimação, de D. Olívia Penteado e sua filha, sem maiores informações sobre seu destino. A imagem que o ilustra mostra um carro, seu chofer e mais dois homens de uniforme branco em uma área ajardinada. A seguir, da esquerda para a direita, entra no plano uma mulher mais velha, certamente D. Olívia, que fecha a sombrinha e ingressa no carro. Depois, sua filha. Atrás delas um homem, provavelmente 
membro da família, que pára diante do automóvel, olha para a câmera e se despede da mulher. $O$ plano seguinte, sem relação imediata com o anterior, nos mostra homens e mulheres conversando em ambiente externo. Não há, entre eles, distinção perceptível na forma pela qual ocupam o espaço. Percebemos que alguns, poucos, estão vestidos para a caça. Nos dois planos finais dessa pequena introdução temos a imagem de sua filha (Maria ou Carolina?) ao lado do cavalo.

Ressalta-se a frouxa ligação entre os planos. Em que medida a partida anunciada se relaciona com as imagens seguintes dos homens e mulheres a conversar e da herdeira do clã ao lado de sua montaria? Poderíamos pensar que a falta de articulação se deve à inabilidade em trabalhar com os procedimentos tidos como constitutivos do cinema narrativo clássico. No entanto, afora o fato de não sabermos quanto do material remanescente corresponde à integralidade do que foi exibido em São Paulo no segundo semestre de 1913, é importante lembrar que vivemos um período em que a consolidação desse cinema estava em construção, sendo Nascimento de uma Nação (1915), de Griffith, considerado um divisor de águas. Ou seja, antes de procurarmos carências, devemos examinar a obra com um olhar que abrigue em seu campo a possibilidade de existir outros modos cinemáticos, distintos de um referencial que estava por se erguer.

Neste sentido, duas considerações devem ser feitas. Em primeiro lugar, a aparente falta de continuidade de ação é substituída por um elemento que nos parece ser o centro efetivo das atenções: os indícios de riqueza, como o carro, os funcionários, o cavalo, as vestimentas de equitação e o pequeno círculo social identificado pela maneira de se portar e vestir. São estes os sinais que devem chamar a nossa atenção, antes de tudo, e esse procedimento é estrutural dentro do filme, como teremos oportunidade de demonstrar.

Em segundo lugar, ao conferir historicidade ao nosso olhar e à obra, percebemos que essa pequena introdução desloca a questão do gênero para outro patamar. Isto pode ser percebido na aproximação a outro filme de época, o registro familiar captado em Um Domingo em Casa de Vovô (1914-1920), produção da mesma Campos Filme. Pela descrição de seu conteúdo feita a partir da película depositada na Cinemateca Brasileira ${ }^{38}$ é lícito afirmar que a obra contém os primeiros planos de Caça, justamente os aqui descritos. Uma vez que aquilo que foi destinado à exibição em cinemas também era visto como produção destinada ao usufruto da família, é válido fazer a diferenciação entre documentário e filme de família? O embaralhar dos registros indica que, no caso das ricas famílias da oligarquia paulista, a distinção entre público e 
privado operava sobre limites tênues, esmaecidos pela vontade de ostentar para a população os elementos definidores de sua condição social.

Esse esmaecimento está na razão de ser do próprio filme, pois exibido no cinema contribui para reforçar no imaginário da população paulistana uma determinada representação dessa elite. Porém, como veremos, essa passagem de um consumo mais restrito de uma imagem familiar para um contexto mais amplo constitui o tema dos próximos segmentos de Caça.

Presenciamos então a partida da comitiva do Palacete Prates, como faz questão de ressaltar o letreiro. Vestidos a caráter, com cornetas e demais apetrechos importados da Inglaterra, mais de quarenta cavaleiros e amazonas desfilam diante da câmera. Vemo-los primeiramente no espaço intramuros do Palacete. A câmera fixa permite que vislumbremos a fachada da mansão à esquerda, enquanto o cortejo passa solenemente diante da construção. À direita, como somos informados visualmente pelo próximo plano, o chafariz.

O ponto de partida não foi escolhido ao acaso. A família Prates, responsável por uma das importantes riquezas do Estado, tinha ligação com as atividades ligadas à equitação. $\mathrm{O}$ Conde de Prates foi o fundador e primeiro presidente da Sociedade Hípica Paulista, criada em 1911 por iniciativa de seu filho, Guilherme Prates, e outros amigos. ${ }^{39}$ A proximidade de Antonio Campos das famílias abastadas de São Paulo o leva por sua vez a registrar outros eventos ligados ao clube e à equitação, como O Concurso Hípico Realizado no Velódromo (1913) e Concurso Hípico no Posto Zootécnico Dr. Carlos Botelho (1913), exibidos no mesmo ano em que Caça chegou às telas. ${ }^{40}$

O contexto que se relaciona ao surgimento da Sociedade Hípica Paulista foi examinado por Mônica Schpun em trabalho sobre os espaços de sociabilidade existentes na cidade de São Paulo nas primeiras décadas do século passado. A autora observa que o crescimento da cidade diminuiu as áreas passíveis de receber atividades eqüestres, provocando a criação de lugares exclusivos e distantes das propriedades fundiárias de cada família. ${ }^{41}$

A estação de "caça à raposa" é oficializada em 1913 pelos sócios da Hípi$\mathrm{Ca}^{42}$ e o filme é provavelmente seu primeiro registro. O primeiro plano da comitiva partindo do Palacete Prates reforça o aspecto de uma atividade restrita a um pequeno número de pessoas vinculadas à riqueza oriunda do café, restrição expressa pelo fato de a iniciativa fazer parte de um clube no qual poucos eram admitidos, sendo a elevada condição social garantia de passaporte de ingresso. Estamos no interior dos limites da mansão, espaço ainda mais exclusivo.

No entanto, o cortejo prossegue. No plano seguinte, a câmera, fixa, está 
situada na parte externa da propriedade, mais precisamente à frente e um pouco à esquerda do portão principal, que se encontra aberto. Percebemos que as grades que separam o que é espaço público do privado são parcialmente preenchidas por chapas de ferro que impedem a visão dos jardins da mansão e demais aspectos do espaço interno por um transeunte na rua, reforçando o caráter de revelação que a imagem anterior possui. Vimos aquilo que era interdito ao olhar. Esse processo de abertura e de convite à participação de uma experiência vivenciada apenas por um pequeno círculo culmina com a partida da entourage, observada por um diminuto, mas curioso, número de populares que está ao lado da saída, espreitando ora a comitiva, ora a câmera. Lá estão eles a funcionar como nosso duplo. Sua reação seria a do espectador na sala de cinema. $\mathrm{O}$ ir às ruas, por sua vez, acentua um aspecto que provavelmente está na origem do projeto fílmico: dar a conhecer ao maior número possível de pessoas os fatores que do ponto de vista simbólico justificariam a existência dessa elite. Ela se apresenta como sofisticada, vinculada àquilo que ainda hoje é entendido como uma prática aristocrática, a saber, a caça à raposa. A unidade de ação conformada pelas vestimentas e pelo caráter de desfile organizado reforça o processo de construção de identidade. Para tanto, é preciso se diferenciar do outro, e o outro se encontra no espaço público, a pé e irmanado pela indumentária mais simples.

O cinema potencializa o significado primeiro desse projeto em diversos sentidos: atinge um número maior de pessoas e mobiliza os recursos de um meio que já é visto sem tantas reservas pela burguesia. A captação desse evento pela máquina cinematográfica amplia o efeito desejado por todo o cerimonial através de procedimentos específicos, como mostramos no exame da seqüência introdutória. O desfile e o filme buscam reforçar nas pessoas que circulam pela cidade a distância que os separa do ponto de vista sócio-econômico.

A indicar a existência de um projeto mais amplo está o fotógrafo que, a pé, sai junto com a comitiva do palacete. Não o vemos em ação, mas é provável que sejam de sua autoria as fotos publicadas em julho de 1913 na revista Careta. ${ }^{43} \mathrm{Na}$ edição do dia 12, temos imagens em planos gerais dos cavaleiros e das amazonas representadas em três momentos: a "caça", a partida da Avenida Paulista, e o cortejo visto do Observatório da Avenida. Na do dia 19, duas que nos mostram o regresso dos que fizeram a "chasse da rapoza". Captados em movimento ou em pose, existe uma clara consciência de que um teatro estava sendo montado, requerendo de cada participante uma performance coesa aos ideais de seu grupo. 
O caráter mediático do evento, atestado pela presença do fotógrafo e do cinegrafista, ganhava nas avenidas da cidade o seu palco. Não vemos no filme a Avenida Paulista. Entretanto, seguimos o cortejo pela Avenida Tiradentes. Não se trata apenas das pessoas que eventualmente passavam pelo Palacete Prates na hora da saída dos cavaleiros e das amazonas. A intenção é, de fato, se mostrar, chegar às pessoas, construindo na chave aristocrática o que no corso carnavalesco de automóveis representava a sintonia com a modernidade: uma burguesia que de olho no futuro fazia questão de mostrar o seu lastro.

Em seguida, acompanhamos o que o letreiro define como "peripécias da caçada”. Em três planos gerais, que se repetem do ponto de vista de sua composição, temos: um espaço situado no campo, sem a presença de ninguém; da direita para a esquerda ingressam na imagem uma amazona seguida pelo restante da comitiva, que vemos passar diante da câmera em sua quase totalidade. Depois, cerca de oito planos dão conta da confraternização entre os convivas antes de um outro letreiro anunciar: "o almoço".

A isto se resumiram as "peripécias" e a "caçada". Nenhum sinal de raposa, animal que motivou a empreitada e que não aparecerá até o final do filme, vivo ou morto. Por um lado, essas ausências dizem muito do cinema brasileiro e de suas precariedades, tal como dissemos atrás. Promete-se no texto escrito algo que a imagem não consegue transmitir. Por outro, cabe trazer agora uma informação relevante para a compreensão do evento e, por sua vez, do filme. Não havia propriamente raposa, mas sim um cavaleiro habilidoso que partia na frente de todos e era o objeto da perseguição. ${ }^{44}$ Este dado não nos permite fugir da constatação há pouco trazida, pois continuamos a não ver as dificuldades, a perseguição e o cavaleiro-raposa. Se o efeito era demonstrar as habilidades dos envolvidos na "caça", o objetivo não foi atendido. No entanto, talvez devêssemos neste caso levar outro aspecto em consideração, em consonância com aquilo que corresponde à estrutura do filme.

Apontamos logo de início a falta de articulação existente nos planos iniciais e procuramos ressaltar que o sentido poderia se encontrar em outra chave, qual seja, a ênfase no mostrar, no chamar a nossa atenção para o que vemos no plano, indício de visibilidade da riqueza pertencente ao universo representado. É possível identificar o mesmo procedimento nessa seqüência. Para avaliarmos esta questão, traremos aqui algumas considerações de ordem histórica sobre o processo de constituição da narrativa cinematográfica.

Na história do cinema houve um período, entre 1903 e 1906, no qual os filmes de perseguição constituíam um gênero popular. ${ }^{45}$ Neles observamos o desenrolar de uma persecução em vários planos, constituindo o deslocamen- 
to das "personagens" o interesse central da obra. Em um primeiro momento, observamos a razão da fuga. A seguir, acompanhamos a tentativa de escapar, impedida pelas pessoas que partem no encalço do fugitivo. Com algumas variações, a estrutura de cada plano do filme se repete: plano geral ou de conjunto que nos mostra a paisagem ou o espaço a ser percorrido; o ingresso do fugitivo por um ponto distante em relação à câmera; os perseguidores em sua trilha; a passagem de todos em sua correria até o momento em que saiam do nosso campo de visão; por fim, o plano desprovido de figuras humanas, tal como no início. Não há corte no interior do plano e a ação é captada de seu início até o seu fim, plano a plano.

Até 1903 predominava a narrativa de um plano só, como atestam, por exemplo, os filmes dos irmãos Lumière. Os filmes de perseguição representaram uma alternativa entre o cinema de atrações e o cinema narrativo, entendido o primeiro a partir de sua ênfase no "sincrético, apresentativo e não linear", formado por "performances cujo objetivo é espantar, maravilhar o espectador, e cuja aparição já é, em si, um acontecimento". "Para Tom Gunning, os filmes de perseguição mostram que "estava em curso uma síntese entre atrações e narrativa ... fornecendo um modelo para a causalidade e para a linearidade assim como para a montagem em continuidade" ${ }^{77}$ Porém, a idéia de atração não era abandonada, pois "as perseguições construíam cada plano como uma verdadeira atração, na medida em que cada plano mostrava o perseguido e os perseguidores tendo que ultrapassar obstáculos variados: cercas, lagos, subidas etc.". ${ }^{48}$

Como dissemos, apesar da caça referida no título, não há imagens de perseguição e de seus obstáculos. No entanto, é possível que não estivesse em pauta a busca de uma narratividade. O que talvez estivesse em jogo era apresentar, numa prática vinculada ainda ao cinema dos primeiros tempos. A exibição de todos os participantes nos planos mencionados tinha por função demonstrar o quanto aqueles homens consideravam "importante esse tipo de prática, seu caráter de lazer refinado, sua sociabilidade restrita, seus equipamentos caros e seus trajes sofisticados, forçosamente importados, enfim, o fato de ela supor a representação de um status social diferenciado"." ${ }^{9}$

Assim como na seqüência introdutória, o interesse deve recair no desfile dos cavaleiros e das amazonas devidamente trajados, no mostrar sua sofisticação, sinal distintivo de sua riqueza. Há, portanto, de maneira involuntária ou não, uma mistura de modos cinematográficos, alicerçado nas condições estruturais de produção.

O filme continua com as cenas referentes ao almoço. Uma constante é o 
uso da panorâmica horizontal a nos mostrar calmamente os membros das famílias envolvidas com a iniciativa, em plano próximo que possibilitava ao público da época identificar feições talvez bem conhecidas.

Não restaram do filme que trabalhamos as imagens referentes à distribuição dos prêmios, informada num dos letreiros remanescentes. Depois, surge novo momento de sociabilidade marcado pelo café servido no bosque, onde mulheres e homens aparentemente conversam como se não houvesse maior distinção de gênero, reforçando o caráter familiar do evento. ${ }^{50}$

Por fim, a partida e o retorno pela Ponte Grande, que não nos é de fato mostrado. Outra lacuna poderia ser referida à representação da volta, apresentada nos últimos quatro planos de Caça. Esse era um momento importante dentro da encenação promovida pela elite paulista, como nos indicam as fotos já mencionadas de Careta. A volta não é muito articulada dentro dos critérios da narratividade, dado que não vemos entre os planos continuidade de ação, refletida na presença de personagens comuns e no estabelecimento de alguma relação causal. Há, no entanto, um mesmo sentido no deslocamento dos cavaleiros e amazonas, pois todos se dirigem da esquerda para a direita.

Uma consideração final nos remete a um aspecto comentado há pouco e diz respeito à necessidade das elites paulistas ligadas à cafeicultura de ocupar o espaço da cidade a fim de corroborar uma determinada imagem de si, representação simbólica ampliada pelas fotografias espalhadas em um periódico de época e pelos fotogramas do cinema. No campo historiográfico é o momento de celebração da figura do bandeirante, fidalgo e ao mesmo tempo pragmático, personagem que permite fortalecer os laços de identidade entre passado e presente por meio daqueles que se vêem como continuadores da ação de fortalecimento da Nação. A chegada dos imigrantes e sua ascensão econômica perturbam o quadro. Indústrias, arranha-céus, mansões e os monumentos funerários, como os construídos no cemitério da Consolação, especialmente os da família Matarazzo e Jafet, mostram um outro lado dessa contenda simbólica. Os cinegrafistas imigrantes, de origem humilde e em uma atividade cultural marginalizada pela sociedade, encontram-se no meio do caminho, embaralhando os referenciais e criando certa indeterminação nas imagens que sobreviveram. Testemunhas de um conflito que transcende o campo da política, seu cinema é, por excelência, o espaço da ambigüidade. 


\section{NOTAS}

${ }^{1}$ Com exceção da análise fílmica de Caça à Raposa (1913), de Antonio Campos, situada ao final deste artigo, o presente texto teve como ponto de partida um programa de trabalho solicitado pela Cinemateca Brasileira, projeto redigido pelo autor e por Ismail Xavier.

${ }^{2}$ Doutor pela Escola de Comunicação e Artes da Universidade de São Paulo.

${ }^{3}$ GOMES, Paulo Emilio Salles. A expressão social dos filmes documentais no cinema mudo brasileiro (1898 - 1930). In: CALIL, C. A. e MACHADO, M. T. (Org.) Paulo Emilio: um intelectual na linha de frente. São Paulo: Brasiliense, Rio de Janeiro: Embrafilme, 1986, p.324. Carlos Roberto de Souza trabalhou recentemente estas questões em Tesouro Mudo, Nossa História, v.1, n.11, p.70-74, set. 2004.

${ }^{4}$ Ver BERNARDET, J.-C. Cinema brasileiro: propostas para uma história. Rio de Janeiro: Paz e Terra, 1979, p.28, principalmente. Estas questões serão retomadas posteriormente em Historiografia clássica do cinema brasileiro. Metodologia e pedagogia. São Paulo: Annablume, 1995, p.25 ss.

${ }^{5}$ Trabalhamos com a $2^{\underline{a}}$ edição, publicada em São Paulo pela Editora Perspectiva em 1985. A primeira edição é de 1976. Salões foi publicado pela Perspectiva em 1981.

${ }^{6}$ BERNARDET, J.-C., Historiografia clássica do cinema brasileiro, cit., p.51-64.

${ }^{7}$ Ibidem, p. 51.

${ }^{8}$ Imagens (co)moventes: fotografia, narrativa e a Comuna de Paris de 1871. In: CHARNEY, L.; SCHWARTZ, V. R. (Org.) O cinema e a invenção da vida moderna. Trad. Regina Thompson. São Paulo: Cosac \& Naify, 2001, p.379.

${ }^{9}$ MORETTIN, E. Os Limites de um Projeto de Monumentalização Cinematográfica: uma análise do filme "Descobrimento do Brasil” (1937), de Humberto Mauro. São Paulo, 2001. Tese (Doutorado) - Escola de Comunicações e Artes, Universidade de São Paulo.

${ }^{10} \mathrm{O}$ livro de Bernardet é Cineastas e imagens do povo (São Paulo: Brasiliense, 1985). A busca de uma contextualização histórica está em, dentre outros, Ana Cristina Cesar, Literatura não é documento (Rio de Janeiro: Funarte, 1980), e José Marinho, Dos Homens e das Pedras, o ciclo do cinema documentário paraibano (1959-1979) (Niterói: Ed. UFF, 1999). O viés autoral se manifesta nos trabalhos de Consuelo Lins, O documentário de Eduardo Coutinho (Rio de Janeiro: Jorge Zahar, 2004), e Carlos Alberto Mattos, Eduardo Coutinho. O Homem que Caiu na Real (Santa Maria da Feira, Portugal: Festival de Cinema Luso Brasileiro de Santa Maria da Feira, 2003), entre outros.

${ }^{11}$ MELO SOUZA, J. I. de, em O Estado contra os meios de comunicação (1889-1945) (São Paulo: Fapesp/Annablume, 2003), e em "Trabalhando com cinejornais: relato de uma experiência”, in: História: Questões \& Debates (Curitiba, UFPR, v.20, n.38, p.43-62, 2003), analisa os cinejornais produzidos pelo Departamento de Imprensa e Propaganda (DIP) getulista. SCHWARZMAN, S., em Humberto Mauro e as imagens do Brasil (São Paulo: Ed. 
Unesp, 2004, p.195 ss), examina a produção documental do Instituto Nacional de Cinema Educativo (INCE), também criado pelo governo de Getúlio Vargas.

${ }^{12}$ São Paulo em Movimento: a representação cinematográfica da metrópole nos anos 20. São Paulo, 1989. Dissertação (Mestrado) — Escola de Comunicações e Artes, Universidade de São Paulo.

${ }^{13}$ Cinema: trajetória no subdesenvolvimento, Rio de Janeiro: Paz e Terra/Embrafilme, 1980, p.77.

${ }^{14}$ MACHADO, R., op. cit., p.45-6, 62-3.

${ }^{15}$ O recente Documentário no Brasil. Tradição e Transformação (São Paulo: Summus, 2004), organizado por TEIXEIRA, F. E., não trata dos documentários que serão analisados neste artigo.

${ }^{16}$ ALMEIDA, G. de. "Afinal”. O Estado de S. Paulo, 25.5.1929 (citado por MACHADO, R., op. cit., p.138).

${ }^{17}$ CINEMATECA BRASILEIRA. Guia de Filmes Produzidos no Brasil entre 1921 e 1925. Rio de Janeiro: Embrafilme, 1987, p.78.

${ }^{18}$ Ibidem, p.78.

${ }^{19}$ Ibidem, p.91. Jurandyr Noronha reproduz um fotograma de filme de Reis sobre a campanha de 1924 onde notamos um soldado calçando chinelos (Cf. No tempo da manivela, Rio de Janeiro: Ed. Brasil-América, Kinart e Embrafilme, 1987, p.113).

${ }^{20}$ MENDES, O. Cinema Brasileiro. Cinearte, v.VII, n.315, p.7, 9.3.1932.

${ }^{21}$ Ver, neste sentido, a análise que Ismail Xavier faz de Intolerância (1916), de Griffith, em "Parábolas cristãs no século da imagem". Imagens, n.5, p.11, ago./dez. 1995, texto reeditado em O Olhar e a Cena. São Paulo: Cosac \& Naify, 2004, p.101-25.

${ }^{22}$ Guia de Filmes Produzidos no Brasil entre 1921 e 1925, p.78. Paulo Emilio Salles Gomes sumaria a campanha movida por Cinearte contra os naturais em Humberto Mauro, Cataguases e Cinearte. São Paulo: Perspectiva, 1974, p.308-10.

${ }^{23}$ Ibidem, p.78.

${ }^{24}$ Citado por BERNARDET, J.-C. em Filmografia do Cinema Brasileiro 1900-1935. Jornal "O Estado de S. Paulo". São Paulo: Governo do Estado de São Paulo, Secretaria da Cultura, Comissão de Cinema, 1979, item '1926 - 8'.

${ }^{25}$ Guia de Filmes Produzidos no Brasil entre 1921 e 1925, p.77. Além desse, temos outros trabalhos que podem ser inseridos dentro deste quadro, tais como: Os Sertões de Mato Grosso (1912/1913), No País das Amazonas (1922), Brasil Grandioso (I) (1923), Terra Encantada (1924), Nas Selvas do Extremo Norte (1925), No Rastro do Eldorado (1925), Brasil Desconhecido (1925), Viagem ao Brasil (1927), O Brasil Maravilhoso (1930), Nos Sertões do Amazonas (1931), O Brasil Grandioso (II) (1931), Ao Redor do Brasil (1932), Nas Florestas Virgens do Amazonas (1933), Do Rio de Janeiro ao Pará (1933) (Cf. CINEMATECA 
BRASILEIRA. Guia de Filmes Produzidos no Brasil entre 1911 e 1920, Rio de Janeiro: Embrafilme, 1985; Guia de Filmes Produzidos no Brasil entre 1921 e 1925, 1987, e BERNARDET, J.-C., Filmografia do Cinema Brasileiro 1900-1935, cit., 1979).

${ }^{26}$ GALVÃO, M. R. Crônica do Cinema Paulistano. São Paulo: Ática, 1975, p.32.

${ }^{27}$ Ibidem, p.54. Sobre a participação de Canuto Mendes no movimento cinematográfico da época ver SALIBA, M. E. F., Cinema contra cinema. O cinema educativo de Canuto Mendes (1922 - 1931). São Paulo: Annablume/Fapesp, 2003.

${ }^{28}$ Orfeu extático na metrópole: São Paulo, sociedade e cultura nos frementes anos 20. São Paulo: Companhia das Letras, 1992, p.105.

${ }^{29}$ Introdução. In: CHARNEY, L.; SCHWARTZ, V. (Org.) O cinema e a invenção da vida moderna, cit., p.22.

${ }^{30}$ Sobre a questão ver XAVIER, I. De monumentos e alegorias políticas: a Babilônia de Griffith e a dos Taviani. In: Estudos de Cinema, v.2, p.125-52, 1999.

${ }^{31}$ Les ailes de l'Histoire. Vertigo. Le cinéma face à l'histoire, n.16, p.8, 1997.

${ }^{32}$ NORA, P. Entre Memória e História. A problemática dos lugares. Projeto História, n.10, p.22, dez. 1993.

${ }^{33}$ Dentro de um processo que pode ser transportado para o caso brasileiro, Nora, ao discutir o trinômio História, memória e Nação, tendo por base a historiografia francesa do século XIX, observa que a "definição nacional do presente chamava imperiosamente sua justificativa pela iluminação do passado" (op. cit., p.11).

${ }^{34}$ LE GOFF, J. Documento/monumento. In: ENCICLOPÉDIA EINAUDI. v.1 - Memória — História. [Lisboa]: Imprensa Nacional/Casa da Moeda,1984, p.102.

${ }^{35}$ Ibidem, p.103, grifos nossos.

${ }^{36}$ TORGAL, L. R. História, divulgação e ficção. In: TORGAL, L. R.; MENDES, J. A.; CATROGA, F. (Org.) História da História em Portugal: séculos XIX e XX. v.2. Lisboa: Ed. Círculo, 1998, p.156-7.

${ }^{37}$ Utilizou-se no estudo a cópia depositada no acervo da Cinemateca Brasileira. É sempre preciso lembrar o fato de que o filme hoje à disposição não corresponde ao material de época, em razão das perdas de fotogramas e de qualidade fotográfica provocadas pela ação do tempo.

${ }^{38}$ Informação levantada em www.cinemateca.gov.br em 30.3.2005. Há nesse site um campo que nos remete à filmografia do cinema brasileiro, contendo fichas técnicas completas, além de informações complementares concernentes à exibição.

${ }^{39}$ Cf. SCHPUN, M. R. Beleza em jogo: cultura física e comportamento em São Paulo nos anos 20. São Paulo: Ed. Senac/Boitempo, 1999, p.55.

${ }^{40}$ ARAÚJO, V. de P., Salões, circos e cinemas de São Paulo, cit., p.232. 
${ }^{41}$ SCHPUN, M., op. cit., p. 55.

${ }^{42}$ Ibidem, p.57.

${ }^{43}$ Ver as edições de 12 jul. e 19 jul. 1913, ano VI, n.267 e 268, sem indicações de página, seção "Careta em S. Paulo".

${ }^{44}$ SCHPUN, M., op. cit., p.57.

${ }^{45}$ As referências ao gênero nesse momento da história do cinema serão retiradas de COSTA, F. C., O primeiro cinema. São Paulo: Scritta, 1995.

${ }^{46}$ Ibidem, p.22-3. O primeiro trecho entre aspas do parágrafo pertence a Charles Musser, citado pela autora.

${ }^{47}$ Citado por COSTA, F. C., op. cit., p.21.

${ }^{48}$ Ibidem, p.21.

${ }^{49}$ SCHPUN, M., cit., p.57-8.

${ }^{50}$ Mônica Raisa Schpun observa que a maior participação feminina nesse tipo de evento ocorria por ser uma atividade menos competitiva, por isso "menos significativa aos olhos do grupo" (p.57). 